OPEN

SUBJECT AREAS:

TUMOUR SUPPRESSORS

POST-TRANSLATIONAL MODIFICATIONS

Received

23 July 2013

Accepted

11 October 2013

Published

31 October 2013

Correspondence and requests for materials should be addressed to X.L. (xin.lu@ludwig.ox. ac.uk)

\section{Requirement for phosphorylation of P53 at Ser312 in suppression of chemical carcinogenesis}

\author{
Elizabeth A. Slee \& Xin Lu
}

Ludwig Institute for Cancer Research, Nuffield Department of Clinical Medicine, University of Oxford, Old Road Campus Research Building, Oxford OX3 7DQ, United Kingdom.

The p53 tumour suppressor is activated in response to a wide variety of genotoxic stresses, frequently via post-translational modification. Using a knock in mouse model with a Ser312 to Ala mutation, we show here that phosphorylation of p53 on Ser312 helps to prevent tumour induction by the alkylating agent MNU, which predominantly caused $\mathrm{T}$ cell lymphomas. This is consistent with our previous observation that p53 $3^{312 \mathrm{~A} / \mathrm{A}}$ mice are more susceptible to X-ray induced tumourigenesis. Phosphorylation on Ser312 aids p53's interaction with E2F1, and enhances p53-mediated apoptosis. Loss of E2F1 alone does not affect tumour susceptibility to MNU, but its absence partially rescues tumour formation in $\mathrm{p} 53^{312 \mathrm{~A} / \mathrm{A}}$ mice, thus reflecting the oncogenic properties of E2F1. Our data confirms the participation of Ser312 phosphorylation in tumour suppression by p53.

-

he p53 pathway is one of the main lines of defence in response to carcinogenic stress, and p53 inactivating mutations frequently arise in tumours. Damage to DNA from radiation or carcinogens causes the stabilisation of p53, which then prevents the transmission of this damage by inducing cell cycle arrest, apoptosis or senescence. p53 is mutated in around 50\% of cancers, and the familial Li-Fraumeni syndrome, which results in an increased susceptibility to cancers, is caused by the inheritance of mutations in the TP53 gene. The importance of p53 in tumour suppression is also reflected in the susceptibility of p53 null mice to spontaneous tumour formation, and the decreased resistance of $\mathrm{p} 53^{+/-}$mice to $\gamma$-radiation exposure ${ }^{1-3}$.

E2F1, like p53, is a transcription factor that impacts upon the cell cycle, senescence, apoptosis and tumour growth, and both are pivotal in two canonical tumour suppression pathways. E2F1 drives entry of the cell into Sphase, and is restrained by its interaction with the tumour-suppressive retinoblastoma protein (Rb). Phosphorylation of $\mathrm{Rb}$ by cyclin dependent kinases releases $\mathrm{E} 2 \mathrm{~F} 1$, allowing it to activate genes required for entry into S-phase. The Rb/E2F pathway is frequently disrupted in tumours, either through loss of Rb, or increased phosphorylation of $\mathrm{Rb}$ either by inactivation of the cyclin dependent kinase inhibitor $\mathrm{p} 16^{\mathrm{INK} 4 \mathrm{a}}$ or amplification of cyclin $\mathrm{D}^{4}$. Because of its role in driving entry into the cell cycle, E2F1 was originally thought to be oncogenic. However, mice lacking E2F1 unexpectedly showed aberrant cell proliferation and tumour development, indicating that E2F1 also has tumour suppressive roles $^{5,6}$.

There is much evidence of cross talk between the $\mathrm{p} 53$ and Rb/E2F1 pathways ${ }^{7}$. Both, for example, are regulated by the CDKN2A locus, which encodes the proteins $\mathrm{p} 16^{\mathrm{INK} 4 \mathrm{a}}$ and $\mathrm{p} 19^{\mathrm{ARF}}$. Whereas p16 ${ }^{\mathrm{INK} 4 \mathrm{~A}}$ inhibits E2F1 by preventing phosphorylation of Rb, p19 ${ }^{\mathrm{ARF}}$ stabilises 53 by inhibiting $\mathrm{Mdm} 2$, an E3 ligase that causes proteasomal degradation of $\mathrm{p} 53$. In turn, E2F1 can activate the expression of $\mathrm{p} 19^{\mathrm{ARF}}$ and cause $\mathrm{p} 53$ stabilisation ${ }^{8}$. Co-operation between $\mathrm{p} 53$ and E2F1 can also occur independently of p19 ${ }^{\mathrm{ARF}}$. The N-terminus of E2F1 can interact directly with a region towards the C-terminus of p53, resulting in increased nuclear retention of $\mathrm{p} 53$ and p53-mediated transcription and apoptosis. This is inhibited by competition between $\mathrm{p} 53$ and cyclin $\mathrm{A}$ at the binding site within $\mathrm{E} 2 \mathrm{~F} 1^{9,10}$. The interaction between $\mathrm{p} 53$ and E2F1 is enhanced by phosphorylation of p53 on Ser315, a residue within the E2F1 binding region that is phosphorylated by cell cycle kinases such as cdk1, cdk2, cdk9 and Aurora kinase $\mathrm{A}^{11-15}$.

Ser315 is one of approximately 20 serine/threonine phosphorylation sites that have been identified within p53 that constitute part of a complex regulatory network of post-translational modifications ${ }^{16}$. Many of these sites are phosphorylated by kinases activated in response to cellular stress, and are located at the N-terminus, the region of p53 that is involved in its stability and transcriptional regulation ${ }^{17}$. Several mouse models have been made that incorporate inactivating mutations at these phosphorylation sites, and their phenotypes are generally mild ${ }^{17,18}$. 
Previously, we have characterised a knock in mouse model that carried a serine to alanine mutation on Ser312 (equivalent to human Ser315). Although these mice are healthy and have a normal lifespan, in response to ionising radiation they develop lymphomas and tumours in the liver ${ }^{19,20}$.

To determine the effect on tumour formation of both deleting E2F1 and preventing phosphorylation of p53 at Ser312, we crossed the p53Ser312Ala mice with E2F1 null mice and exposed them to a DNA alkylating agent, $N$-Methyl- $N$-nitrosourea (MNU). As was observed when these mice were exposed to ionising radiation, the p53 $312 \mathrm{~A} / \mathrm{A}$ mice are more susceptible to tumour formation. Loss of E2F1 alone did not render these mice more susceptible to tumours, but loss of E2F1 had a slightly protective effect upon the tumour formation seen in $\mathrm{p} 53^{312 \mathrm{~A} / \mathrm{A}}$ mice. Our study shows that in addition to protecting against tumours caused by ionising radiation, phosphorylation of p53 on Ser312 also contributes to the suppression of carcinogen-mediated tumourigenesis.

\section{Results}

We generated the mice for this study by intercrossing $\mathrm{p} 53^{312 \mathrm{~A} /+}$; $\mathrm{E} 2 \mathrm{~F} 1^{+1-}$ mice. The mice were born at the expected Mendelian frequency and showed no gross abnormalities (Table 1). Both males and females were born at close to the predicted numbers. None of the mice developed spontaneous tumours within the time frame examined.

We previously observed that $\mathrm{p} 53^{312 \mathrm{~A} / \mathrm{A}}$ mice are more susceptible to tumour formation than wild type mice following exposure to ionising radiation ${ }^{19}$. To determine if these mice are susceptible to other carcinogens, and whether the presence or absence of E2F1 affects this susceptibility, we gave 4-6 week old mice a single dose of the alkylating agent $N$-Methyl- $N$-nitrosourea (MNU). The study group consisted of 18 wild type ( 7 females and 11 males), 13 p53 $3^{312 \mathrm{~A} / \mathrm{A}}$ ( 9 females and 4 males), $13 \mathrm{E} 2 \mathrm{~F}^{-/-}$(6 females and 7 males) and $12 \mathrm{p} 53^{312 \mathrm{~A} / \mathrm{A}}$; $\mathrm{E} 2 \mathrm{~F} 1^{-1-}$ ( 6 females and 6 males). The mice were culled either when they showed signs of poor health or at 20 weeks post-injection when the study was terminated.

The mice began to develop tumours at 10-11 weeks post injection (Figure 1). Mice of all genotypes developed tumours, but p53 $312 \mathrm{~A} / \mathrm{A}$ mice were significantly more susceptible to tumours than both wild type and $\mathrm{E} 2 \mathrm{~F} 1^{-1-}$ mice, with $p$ values of 0.0021 and 0.0146 respectively (Figure 1A and B). p53 $3^{312 \mathrm{~A} / \mathrm{A}}$ mice developed tumours within a shorter time frame than either wild type and $\mathrm{E} 2 \mathrm{~F} 1^{-1-}$ mice, and in the wild type mice in particular, the existence of a tumour was asymptomatic and only detected post-mortem at 20 weeks. Not all mice developed tumours within the time frame of this study, although only one p53 $3^{312 \mathrm{~A} / \mathrm{A}}$ mouse was tumour-free at 20 weeks. p53 $312 \mathrm{~A} / \mathrm{A}$; $\mathrm{E} 2 \mathrm{~F}^{-1-}$ mice developed tumours earlier than wild type mice, although this was not significant (Figure 1C). Although fewer p53 $312 \mathrm{~A} / \mathrm{A} ; \mathrm{E} 2 \mathrm{~F} 1^{-1-}$ mice than $\mathrm{p} 53^{312 \mathrm{~A} / \mathrm{A}}$ mice developed tumours, again this difference was not significant (Figure 1D). There was little

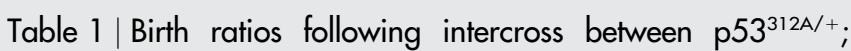
$\mathrm{E} 2 \mathrm{Fl}^{+/-}$mice. Figures in brackets represent predicted numbers based on Mendelian segregation

\begin{tabular}{|lcccc} 
& E2F1 & MALE & FEMALE & TOTAL \\
\hline p53 $^{\text {WT }}$ & WT & $10(9)$ & $8(9)$ & $18(17)$ \\
& $+/-$ & $24(17)$ & $13(18)$ & $37(35)$ \\
$\mathbf{p 5 3}^{312 A /+}$ & $-/-$ & $6(9)$ & $9(9)$ & $15(17)$ \\
& WT & $19(17)$ & $20(18)$ & $39(35)$ \\
& $+/-$ & $41(35)$ & $35(35)$ & $76(70)$ \\
$\mathbf{p 5 3}^{3124 / A}$ & $-/-$ & $16(17)$ & $10(18)$ & $26(35)$ \\
& WT & $12(9)$ & $15(9)$ & $27(17)$ \\
& $+/-$ & $8(17)$ & $18(18)$ & $26(35)$ \\
& $-/-$ & $5(9)$ & $10(9)$ & $15(17)$ \\
& & 141 & 138 & 279 \\
\hline
\end{tabular}

difference in tumour susceptibility between $\mathrm{E} 2 \mathrm{~F} 1^{-1-}$ and wild type mice (Figure 1E).

The predominant tumour type developed by mice of all genotypes was lymphoma, observable mainly as a grossly enlarged thymus that had lost its normal corticomedullary architecture, but also disseminated lymphomas that infiltrated organs such as the spleen, liver, kidney and lung (Figure 2A). This was observed as enlargement, pallor and mottling of the affected organs, with the thymus remaining unaffected. 8/19 (42.1\%) wild type mice developed lymphomas, and 6/19 (31.6\%) developed lung tumours which were almost always found at 20 weeks, with 5/19 (26.3\%) showing no tumour development. One wild type mouse was found to have an abnormal liver at the end of the study. Of the p53 $312 \mathrm{~A} / \mathrm{A}$ cohort, $9 / 12$ mice $(75.0 \%)$ developed lymphomas, $2 / 12(16.6 \%)$ had lung tumours and one mouse was tumour-free. 5/13 (38.5\%) E2F1 $1^{-1-}$ mice developed lymphomas (including one mouse that had both thymic lymphoma and lung tumour), but $8 / 13(61.5 \%)$ finished the study without developing tumours. 8/12 p53 $33^{312 \mathrm{~A} / \mathrm{A}}$; E2 $\mathrm{F}^{-1-}$ mice (66.7\%) developed lymphomas, $2 / 12(16.6 \%)$ developed lung tumours (again one mouse had both thymic lymphoma and a lung tumour) and 3/12 (25.0\%) mice carried no tumours. Almost all the lung tumours (bronchioalveolar adenoma) were found at the end of the study and the incidence of lung tumours between the four groups was not significantly different (data not shown). Therefore, nearly all the $\mathrm{p} 53^{312 \mathrm{~A} / \mathrm{A}}$ mice developed tumours (91.6\%), compared with $73.1 \%$ of wild type mice, $75 \%$ of $\mathrm{p} 53^{312 \mathrm{~A} / \mathrm{A}}$; E2F1 ${ }^{-1-}$ mice and only $38.5 \% \mathrm{E} 2 \mathrm{~F} 1^{-1-}$ mice.

Reflecting the trend of overall tumour incidence, $\mathrm{p} 53^{312 \mathrm{~A} / \mathrm{A}}$ mice were significantly more susceptible to lymphoma development than both wild type and $\mathrm{E} 2 \mathrm{~F} 1^{-1-}$ mice $(p=0.0106$ and $p=0.0359$ respectively) (Figures $2 \mathrm{~B}$ and $\mathrm{C}$ ). The median time of onset for lymphoma in $\mathrm{p} 53^{312 \mathrm{~A} / \mathrm{A}}$ mice was 112 days compared with over 140 days for wild type mice (fewer than $50 \%$ wild type mice had developed lymphomas at the end of the study). More p53 $3^{312 \mathrm{~A} / \mathrm{A}} ; \mathrm{E} 2 \mathrm{~F} 1^{-/-}$mice developed lymphomas than wild type mice (Fig. 2A), although this was not significant $(p=0.194)$. All lymphomas were CD3 positive T cell lymphomas (Figure 2D): staining for the B cell marker CD45R/ B220 was only found at a low level (data not shown).

In addition to thymic hyperplasia, lymphocytes were also frequently found in organs such as the kidneys, liver, lungs and spleen. Table 2 summarises according to genotype the organs where lymphocytes were found in mice carrying a thymic lymphoma. The extent of metastasis was similar for lymphomas from wild type, $\mathrm{p} 53^{312 \mathrm{~A} / \mathrm{A}}$ and $\mathrm{p} 53^{312 \mathrm{~A} / \mathrm{A}} ; \mathrm{E} 2 \mathrm{~F} 1^{-/-}$mice. In addition to the organs listed in the table, lymphoma was found to have spread to the lymph nodes in two wild type mice and two $\mathrm{p} 53^{312 \mathrm{~A} / \mathrm{A}}$ mice.

The 533 cDNAs from 22 of the tumours isolated in this study were extracted and sequenced, and tumour $545\left(\mathrm{E} 2 \mathrm{~F}^{-1-}\right)$ was the only tumour found to have a mutation in the p53 open reading frame $($ GGA $\rightarrow$ GAA/Gly $\rightarrow$ Glu at codon 263) (Figure 3A). To analyse p53 levels in MNU-induced lymphomas, lysates were prepared from these tumours for analysis by immunoblotting (Figure 3B). p53 expression was retained in all the tumours analysed. The levels of total p53 were not especially high, except for tumour 545, which correlates with it carrying an inactivating mutation. Phosphorylation on p53 serine 312 could not be detected (data not shown), as found previously when trying to detect phosphoserine 312 in mouse embryonic fibroblasts ${ }^{19}$. E2F1 levels were also examined. E2F1 levels were low in normal thymus, but were elevated in some of the tumours derived from mice with wild type E2F1, indicating that E2F1 conferred a growth advantage in these circumstances, especially where p53 was mutant. Those tumours from the p53 $3^{312 \mathrm{~A} / \mathrm{A}}$ cohort that expressed high levels of E2F1 (e.g. numbers 467,511 and 520) tended to die at an earlier time point and also with less lymphocyte spread to peripheral organs than those with lower levels of E2F1 (e.g. number 537) (Table 2). Other than where p53 was mutant (545), loss of E2F1 did not substantially elevate p53 levels. 

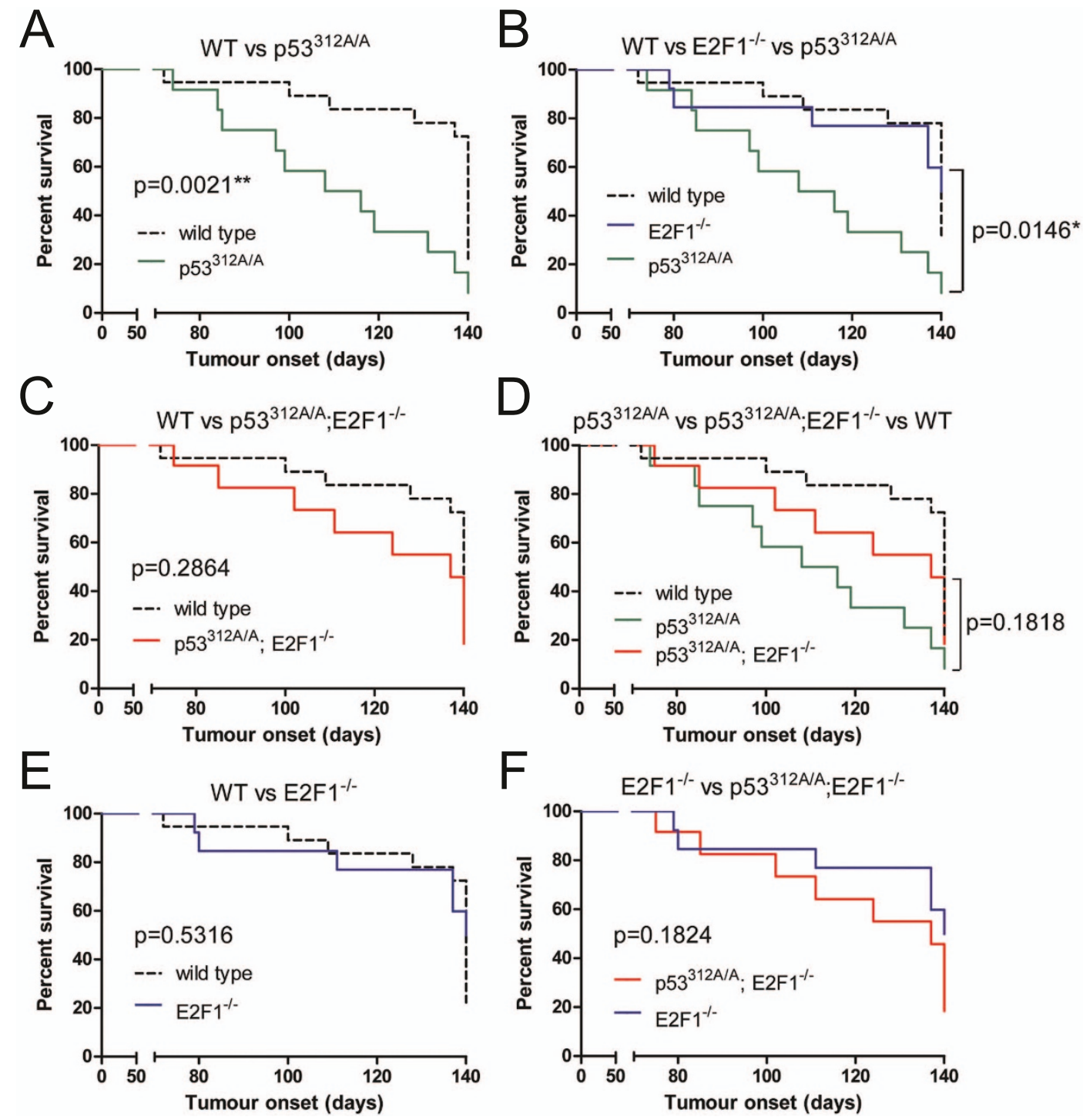

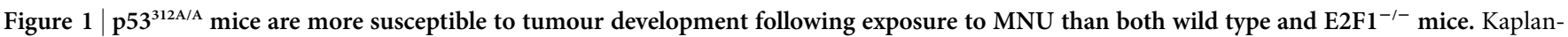
Meier survival curves illustrating the time taken to develop tumours following injection with MNU. p53 $3^{312 \mathrm{~A} / \mathrm{A}}$ mice are significantly more liable to develop tumours than both wild type $(\mathrm{A})$ and $\mathrm{E} 2 \mathrm{~F}^{-1-}(\mathrm{B})$ mice $(p<0.05)$. In contrast $\mathrm{p} 53^{312 \mathrm{~A} / \mathrm{A}}$; E2 $\mathrm{F}^{-/-}$mice are neither significantly more susceptible to tumours than wild type mice $(\mathrm{C})$ nor significantly more resistant than $\mathrm{p} 53^{312 \mathrm{~A} / \mathrm{A}}$ mice $(p>0.05)(\mathrm{D})$. Loss of E2F1 alone had little effect upon tumour susceptibility compared with both wild type (E) and $\mathrm{p} 53^{312 \mathrm{~A} / \mathrm{A}} ; \mathrm{E} 2 \mathrm{~F}^{-1-}$ mice (F).

To analyse proliferation levels in this panel of tumours, phosphorylation of Histone $\mathrm{H} 3$ on serine 10 was used as a marker of mitosis (Figure 3B). There appeared to be little correlation between levels of histone phosphorylation and genotype, other than lower p53 levels correspond with higher levels of phosphorylation as would be predicted from p53's role in preventing cell cycle progression.

Taken together, this data reinforces our previous finding that preventing phosphorylation of p53 on serine 312 reduces its efficacy as a tumour suppressor, as alteration of this residue to alanine both increases the proportion of mice that develop tumours in response to the carcinogen MNU and reduces time of onset.

\section{Discussion}

In this study we analysed the susceptibility to carcinogen-mediated tumour formation of mice lacking the ability to phosphorylate p53 on Ser312, and the impact upon this of E2F1 loss. We found that $\mathrm{p} 53^{312 \mathrm{~A} / \mathrm{A}}$ mice are significantly more susceptible to tumour development than both wild type and $\mathrm{E} 2 \mathrm{~F} 1^{-1-}$ mice in response to the alkylating agent MNU. While p53 $3^{312 \mathrm{~A} / \mathrm{A}}$ mice are more susceptible than either wild type or E2F1 $1^{-1-}$ mice, this is not significant, and they are less vulnerable to tumours than $\mathrm{p} 53^{312 \mathrm{~A} / \mathrm{A}}$ mice.

MNU has been widely used in rodent tumour models and has been reported to cause tumours in a range of tissues including the gastrointestinal tract, lung, nervous system, pancreas and mammary gland $\mathrm{s}^{21}$. The tumours observed in this study were predominantly lymphomas. Lymphomas, especially of the thymus, are a common tumour type found in mice carrying mutations in the $\mathrm{p} 53$ pathway ${ }^{1,2}$, and in a previous study such lymphomas were found in p53 $312 \mathrm{~A} / \mathrm{A}$ mice exposed to ionising radiation ${ }^{19}$. Lymphomas are also the predominant tumour type arising in $\mathrm{p}^{53^{+/-}}$mice dosed with $\mathrm{MNU}^{22-25}$. As in the present study, the lymphomas in $\mathrm{p} 53^{+/-}$mice were CD3positive and $\mathrm{B} 220$ negative $\mathrm{e}^{22}$. Although the predominant cause of death in $\mathrm{p} 3^{+/-}$mice was lymphoma, other tumour types that were not seen in our study were also found, principally adenomas and adenocarcinomas of the intestine. Conversely, no lung neoplasms were observed in these other studies ${ }^{22-25}$. This may be attributable to strain differences, as these studies were all carried out using mice with a C57BL/6 background, whereas the mice used in this study were on a mixed genetic background. 

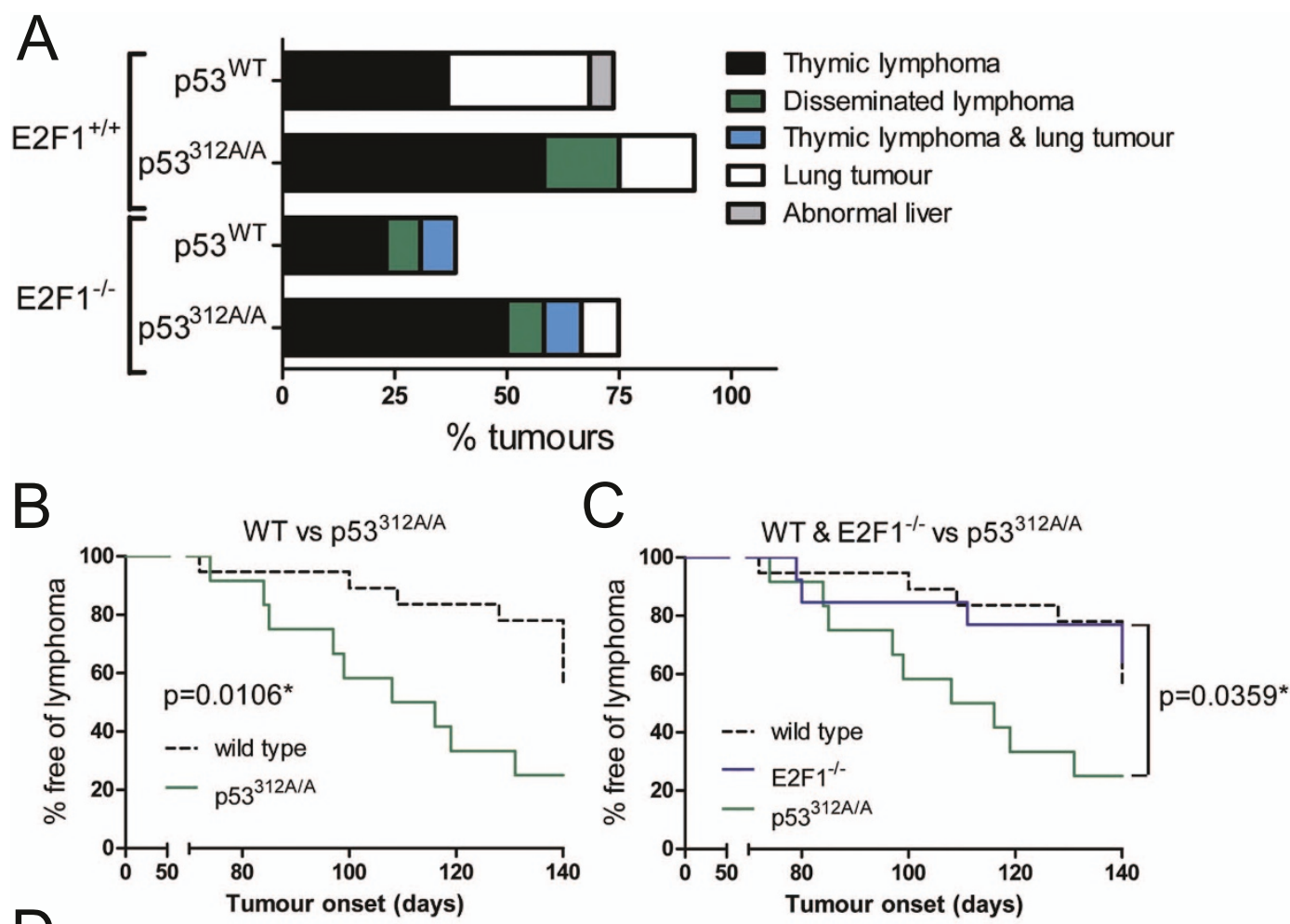

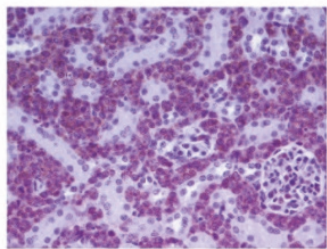

kidney

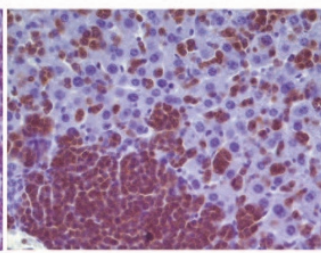

liver

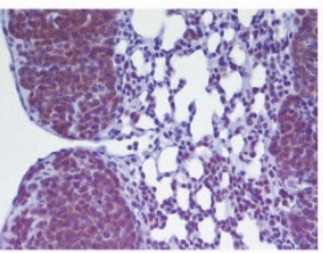

lung

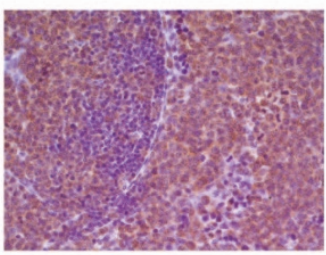

spleen

Figure $2 \mid \mathrm{p} 53^{312 \mathrm{~A} / \mathrm{A}}$ mice are more susceptible to lymphomas following exposure to MNU. (A) Tumour types found in mice exposed to MNU. p53 $3^{312 \mathrm{~A} / \mathrm{A}}$ mice are significantly more susceptible to MNU-induced lymphomas compared with both wild type (B) and E2F1 $1^{-1-}$ mice $(\mathrm{C})(p<0.05)$.

(D) Infiltration of CD3- positive T cell lymphomas into the lung, kidney, liver and spleen in mice exposed to MNU.

Also, the time of tumour onset for the $\mathrm{p} 53^{+/-}$mice is comparable to that seen with the $\mathrm{p} 53^{312 \mathrm{~A} / \mathrm{A}}$ mice used in this study: the earliest onset with the $\mathrm{p}^{23^{+/-}}$mice is between 56 days and 75 days $^{22,23}$ versus 74 days for the p53 $53^{312 A / A}$ mice, and a median survival of 106 days $^{24}$ compared with 112 days with the $\mathrm{p} 53^{312 \mathrm{~A} / \mathrm{A}}$ mice. This is akin to the

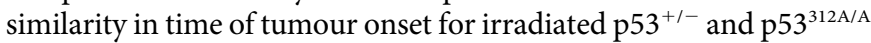
mice ${ }^{3,19}$. p53 is thought to suppress tumours in the thymus by inducing apoptosis, as p53 null mice develop spontaneous lymphomas, and thymocytes derived from these mice are resistant to apoptosis induced by DNA damage ${ }^{1,2,26,27}$. However, thymocytes derived from $\mathrm{p} 53^{312 \mathrm{~A} / \mathrm{A}}$ mice are not resistant to DNA damage and $\mathrm{p} 53^{312 \mathrm{~A} / \mathrm{A}}$ mice do not develop lymphomas spontaneously ${ }^{19}$. A previous study that exposed $\mathrm{p} 3^{+/-}$mice to $\mathrm{MNU}$ found that many of the resulting tumours had lost the remaining p 53 allele ${ }^{25}$, however all the tumours analysed in the current study retained p53 expression and p53 was only found to be mutated in one instance, a G263E mutation in the DNA binding domain (Figure 3 ). This suggests that p53Ser312 phosphorylation is suppressing tumours by other means. Likewise, thymocytes from $\mathrm{E} 2 \mathrm{~F}^{-1-}$ mice are also sensitive to DNA damageinduced apoptosis ${ }^{28}$. It should be noted that mice carrying mutations at other p53 phosphorylation sites, e.g. Ser18, Ser23, or Ser389, have not been reported to develop $\mathrm{T}$ cell lymphomas ${ }^{29-31}$. However, it is very rare to find p53 phosphorylation sites mutated in tumours. These phosphorylation sites, as well as Ser312, lie outside the DNA binding domain of $\mathrm{p} 53$ which is the region where most tumourderived mutations occur. Missense mutations within this region prevent p53 from binding to DNA and altering gene expression, whereas p53 phosphorylation mutants all retain some transcriptional activity ${ }^{19,31-34}$. Mice that have had inactivating tumour-derived mutations introduced e.g. $\mathrm{p} 53^{\mathrm{R} 172 \mathrm{H}}$ and $\mathrm{p} 53^{\mathrm{R} 270 \mathrm{H}}$ mice, spontaneously display a range of tumour types even when heterozygous ${ }^{35,36}$, reflecting the important contribution made by p53 mutations in the DNA binding domain towards tumour growth. Interestingly, the G263E mutation found in our study (equivalent to human G266E) is a deleterious mutation that has been found in tumours derived from tissues including lung and breast, although not at a high rate ${ }^{37}$.

Deletion of E2F1 in the mice used in this study did not affect their susceptibility to tumour development in comparison with wild type mice (Figures 1E, 2C). p53 312A/A $; E 2 \mathrm{~F}^{-1-}$ mice developed more tumours than $\mathrm{E} 2 \mathrm{~F} 1^{-/-}$mice, but fewer than $\mathrm{p} 53^{312 \mathrm{~A} / \mathrm{A}}$ mice (Figures 1D, 1F), although not to a significant degree. p53, when phosphorylated on Ser312, has been shown to compete with cyclin A in its interaction with $\mathrm{E} 2 \mathrm{~F}^{9}$. In the wild type scenario, phosphorylation of $\mathrm{p} 53$ on Ser 312 enables interaction with E2F1 which leads to increased nuclear retention of $\mathrm{p} 53$, cell death and tumour suppres$\operatorname{sion}^{10}$. In the absence of Ser312 phosphorylation in p53 $3^{312 \mathrm{~A} / \mathrm{A}}$ mice, this death pathway should fail to activate, facilitating cell survival and promoting tumour development. With $\mathrm{E} 2 \mathrm{~F}^{-1-}$ mice, wild type p53 
Table 2 | The extent of infiltration of peripheral organs by lymphocytes in mice that developed thymic lymphomas following exposure to $\mathrm{MNU}$. An asterisk indicates sacrifice of the animal at the end of the study (20 weeks)

\begin{tabular}{|c|c|c|c|c|c|c|}
\hline Genotype & Mouse & $\begin{array}{c}\text { Time of } \\
\text { tumour } \\
\text { onset }\end{array}$ & Lung & Liver & Kidney & Spleer \\
\hline \multirow[t]{9}{*}{ wild type } & 458 & 128 & $Y$ & $Y$ & $Y$ & $Y$ \\
\hline & 483 & 100 & - & - & - & - \\
\hline & 497 & $140 *$ & $Y$ & - & - & - \\
\hline & 527 & 72 & $Y$ & $Y$ & $Y$ & $Y$ \\
\hline & 555 & $140 *$ & Y & $Y$ & $Y$ & Y \\
\hline & 600 & $140 *$ & - & - & - & - \\
\hline & 616 & $140 *$ & $Y$ & - & $Y$ & - \\
\hline & 619 & $140 *$ & $Y$ & $Y$ & $Y$ & $Y$ \\
\hline & 670 & 109 & $Y$ & $Y$ & $Y$ & Y \\
\hline \multirow[t]{7}{*}{ p53 $33^{312 A / A}$} & 467 & 115 & - & $Y$ & - & Y \\
\hline & 470 & 116 & $Y$ & $Y$ & $Y$ & Y \\
\hline & 489 & 108 & $Y$ & $Y$ & $Y$ & $Y$ \\
\hline & 511 & 85 & $Y$ & - & - & - \\
\hline & 520 & 97 & - & - & - & $Y$ \\
\hline & 537 & 131 & $Y$ & $Y$ & $Y$ & $Y$ \\
\hline & 584 & 74 & $Y$ & $Y$ & $Y$ & - \\
\hline \multirow[t]{4}{*}{ E2F 1-/- } & 479 & 80 & $Y$ & $Y$ & $Y$ & $Y$ \\
\hline & 545 & 111 & - & - & - & - \\
\hline & 562 & $140 *$ & - & - & - & - \\
\hline & 590 & $140 *$ & $Y$ & $Y$ & $Y$ & $Y$ \\
\hline \multirow{7}{*}{$\begin{array}{l}\text { P53 } 3^{312 A / A} ; \\
\text { E2F 1 } 1^{-1-}\end{array}$} & 456 & 137 & - & - & - & - \\
\hline & 506 & 102 & $Y$ & $Y$ & $Y$ & $Y$ \\
\hline & 521 & 75 & $Y$ & $Y$ & $Y$ & $Y$ \\
\hline & 567 & $140 *$ & $Y$ & - & - & $Y$ \\
\hline & 575 & 111 & $Y$ & $Y$ & $Y$ & $Y$ \\
\hline & 580 & 124 & $Y$ & $Y$ & $Y$ & $Y$ \\
\hline & 663 & 85 & - & - & $Y$ & - \\
\hline
\end{tabular}

is still able to cause apoptosis by E2F1-independent means, as the Ser312Ala mutation is only subtle and does not abrogate the majority of $\mathrm{p} 53$ 's functions ${ }^{19}$. However while the p53-phosphoSer312-E2F1 death pathway cannot activate in $\mathrm{p} 53^{312 \mathrm{~A} / \mathrm{A}} ; \mathrm{E} 2 \mathrm{~F} 1^{-1-}$ mice, the loss of E2F1 may also restrict proliferation and counteract tumour formation when compared to $\mathrm{p} 53^{312 \mathrm{~A} / \mathrm{A}}$ mice, where $\mathrm{E} 2 \mathrm{~F} 1$ is present. This is indicated by the relationship between E2F1 levels and lymphocyte infiltration with or without E2F1 in $\mathrm{p} 53^{312 \mathrm{~A} / \mathrm{A}}$ mice. The primary symptom of thymic lymphoma that requires an animal to be sacrificed is laboured respiration due to constriction of the lungs by the tumour. As shown in Figure $3 \mathrm{~B}$ and Table 2, p53 $3^{312 \mathrm{~A} / \mathrm{A}}$ mice with tumours with high E2F1 levels tended to have shorter lifespans and thymic lymphomas that did not infiltrate other organs (e.g. 511 and 520), perhaps suggesting that the tumours in these mice grew to a critical size within the thoracic cavity before lymphocyte migration to other organs was able to occur. In contrast p53 $33^{312 \mathrm{~A} / \mathrm{A}}$ mice with low E2F1 levels (e.g. 537) died at a later stage with increased lymphocyte infiltration. This is reflected in the double mutant $\mathrm{p} 53^{312 \mathrm{~A} / \mathrm{A}} ; \mathrm{E} 2 \mathrm{~F} 1^{-/-}$mice, most of which also displayed extensive lymphocyte infiltration.

Data generated from studies that have crossed p53 null mice with E2F1 null mice have proved inconsistent. In one study, the deletion of E2F1 abolished the susceptibility of $\mathrm{p} 53^{-1-}$ mice to spontaneous thymic lymphomas ${ }^{28}$, whereas another study found that the loss of E2F1 had no effect ${ }^{38}$. One likely explanation is that two different E2F1 knockout mouse strains were used in these studies. The strain used by Wikonkal et $\mathrm{al}^{5,28}$. is also the strain used in the present study, so the partial rescue of the tumour susceptibility of $\mathrm{p} 53^{312 \mathrm{~A} / \mathrm{A}}$ mice by E2F1 deletion is consistent with their observations. Genetic background may also play a part, as another study crossing $\mathrm{p} 53^{-1-}$ mice with the $\mathrm{E} 2 \mathrm{~F} 1^{-1-}$ mice described by Field et al. but on a different strain background found that although overall survival was not

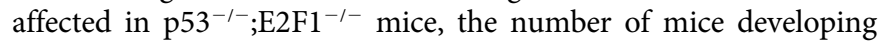

A

tumour 545 codon 263

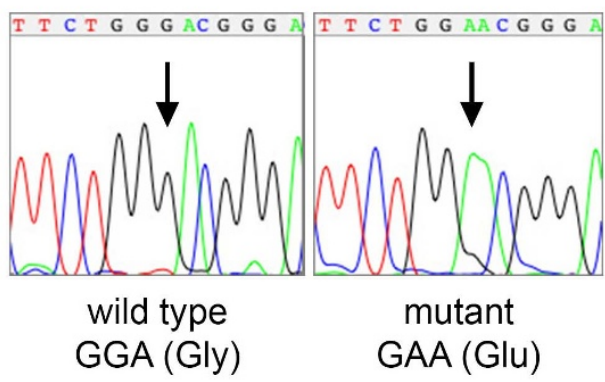

B

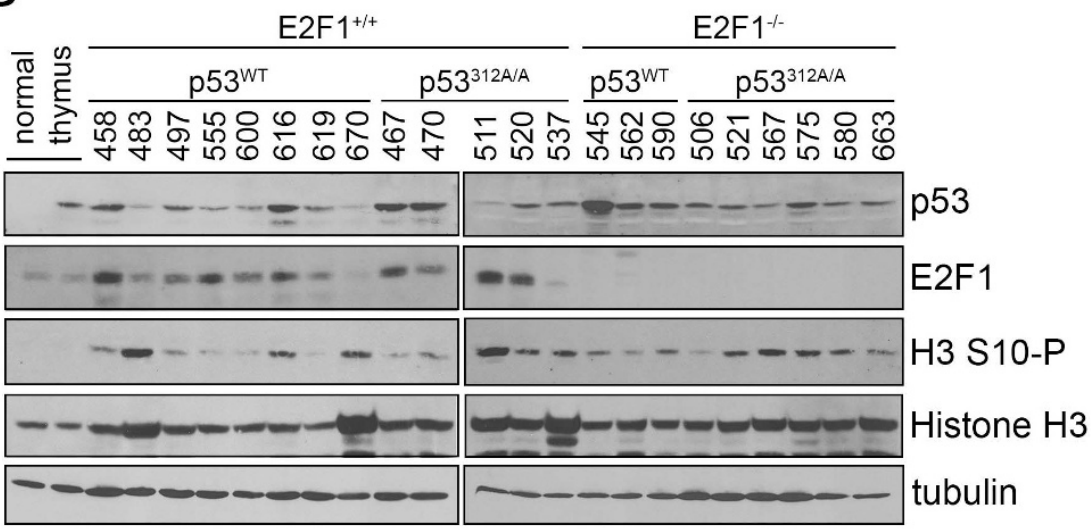

Figure 3 Variations in protein expression in thymic lymphomas derived from mice exposed to MNU. (A) Chromatogram showing the Gly to Glu point mutation found in tumour 545. (B) Immunoblots of tumour lysates derived from thymic lymphomas arising in mice exposed to MNU. Larger versions of these blots are shown in Supplementary Figure 1. 
lymphomas was reduced with a corresponding increase in sarcomas and carcinomas ${ }^{5,39}$.

In conclusion, we observed an increased susceptibility to lymphoma formation induced by MNU in p53 knock in mice carrying a Ser312 to Ala mutation. This strengthens our previous observation that these mice are susceptible to tumourigenesis after exposure to ionising radiation. Thus, phosphorylation on Ser312 enables p53 to fully function as a tumour suppressor.

\section{Methods}

Mice, tumour induction and analysis. E2F1 null mice described by Field et al. were obtained from The Jackson Laboratory ${ }^{5}$. $\mathrm{p} 53^{312 \mathrm{~A} / \mathrm{A}}$ knock in mice were described previously ${ }^{19}$. The mice were on a mixed C57BL/6; 129/Sv; FVB strain background. All animal breeding, maintenance and procedures were approved by the University of Oxford ethical committee and licensed by the U.K. Home Office.

4-6 week old mice were given a single intraperitoneal dose of $N$-Methyl- $N$-nitrosourea (MNU) (Sigma) in citrate buffered saline at $50 \mathrm{mg} / \mathrm{kg}$. The mice were sacrificed either upon ill health or at 20 weeks post-injection. Following sacrifice, tissues were fixed and embedded in paraffin for histological analysis as described previously ${ }^{40}$ or frozen on liquid nitrogen for biochemical analysis. Statistical significance was determined using the Log-rank (Mantel-Cox) test and GraphPad Prism software.

Immunohistochemistry and immunoblotting. Antibodies used were: anti-CD3 and $\beta$-tubulin (Abcam); anti-CD45R/B220 (BD Pharmingen); anti-p53 CM5 (Leica); anti-E2F1 and Histone H3 (Cell Signalling Technologies); Histone H3 phosphoSer10 (Millipore).

Blocking Reagent (Roche) was used to block tissue sections and as antibody vehicle. Signal was developed using the ABC system and diaminobenzidine (Vector Laboratories). Tumour lysates were prepared by homogenising tissue samples in NETN buffer (50 mM Tris pH8.0, $150 \mathrm{mM} \mathrm{NaCl}, 1 \mathrm{mM}$ EDTA, 1\% NP40) containing protease and phosphatase inhibitors.

1. Donehower, L. A. et al. Mice deficient for p53 are developmentally normal but susceptible to spontaneous tumours. Nature 356, 215-221 (1992).

2. Jacks, T. et al. Tumor spectrum analysis in p53-mutant mice. Curr Biol 4, 1-7 (1994)

3. Kemp, C. J., Wheldon, T. \& Balmain, A. p53-deficient mice are extremely susceptible to radiation-induced tumorigenesis. Nat Genet 8, 66-69 (1994)

4. Burkhart, D. L. \& Sage, J. Cellular mechanisms of tumour suppression by the retinoblastoma gene. Nat Rev Cancer 8, 671-682 (2008).

5. Field, S. J. et al. E2F-1 functions in mice to promote apoptosis and suppress proliferation. Cell 85, 549-561 (1996)

6. Yamasaki, L. et al. Tumor induction and tissue atrophy in mice lacking E2F-1. Cell 85, 537-548 (1996).

7. Polager, S. \& Ginsberg, D. p53 and E2f: partners in life and death. Nat Rev Cancer 9, 738-748 (2009).

8. Bates, S. et al. p14ARF links the tumour suppressors RB and p53. Nature 395, 124-125 (1998)

9. Hsieh, J. K. et al. Novel function of the cyclin A binding site of E2F in regulating p53-induced apoptosis in response to DNA damage. Molecular and cellular biology 22, 78-93 (2002).

10. Fogal, V., Hsieh, J. K., Royer, C., Zhong, S. \& Lu, X. Cell cycle-dependent nuclear retention of p53 by E2F1 requires phosphorylation of p53 at Ser315. Embo J 24, 2768-2782 (2005).

11. Bischoff, J. R., Friedman, P. N., Marshak, D. R., Prives, C. \& Beach, D. Human p53 is phosphorylated by p60-cdc2 and cyclin B-cdc2. Proc Natl Acad Sci U S A 87, 4766-4770 (1990).

12. Wang, Y. \& Prives, C. Increased and altered DNA binding of human $\mathrm{p} 53$ by $\mathrm{S}$ and G2/M but not G1 cyclin-dependent kinases. Nature 376, 88-91 (1995).

13. Katayama, H. et al. Phosphorylation by aurora kinase A induces Mdm2-mediated destabilization and inhibition of p53. Nat Genet 36, 55-62 (2004).

14. Radhakrishnan, S. K. \& Gartel, A. L. CDK9 phosphorylates p53 on serine residues 33, 315 and 392. Cell Cycle 5, 519-521 (2006).

15. Qu, L. et al. Endoplasmic reticulum stress induces p 53 cytoplasmic localization and prevents $\mathrm{p} 53$-dependent apoptosis by a pathway involving glycogen synthase kinase-3beta. Genes Dev 18, 261-277 (2004).

16. Murray-Zmijewski, F., Slee, E. A. \& Lu, X. A complex barcode underlies the heterogeneous response of $\mathrm{p} 53$ to stress. Nat Rev Mol Cell Biol 9, 702-712 (2008).

17. Jenkins, L. M., Durell, S. R., Mazur, S. J. \& Appella, E. p53 N-terminal phosphorylation: a defining layer of complex regulation. Carcinogenesis 33, 1441-1449 (2012)

18. Toledo, F. \& Wahl, G. M. Regulating the p53 pathway: in vitro hypotheses, in vivo veritas. Nat Rev Cancer 6, 909-923 (2006).

19. Slee, E. A. et al. Phosphorylation of Ser312 contributes to tumor suppression by p53 in vivo. Proc Natl Acad Sci U S A 107, 19479-19484 (2010).
20. Slee, E. A. \& Lu, X. In the right place at the right time: analysis of p53 serine 312 phosphorylation in vivo. Cell Cycle 10, 1345-1346 (2011).

21. National Institute of Environmental Health Sciences. Report on Carcinogens: Carcinogen Profiles (National Institute of Environmental Health Sciences, Durham, N.C., 2000).

22. Morton, D. et al. N-Methyl-N-Nitrosourea (MNU): A positive control chemical for p53+/- mouse carcinogenicity studies. Toxicol Pathol 36, 926-931 (2008).

23. Hoivik, D. J. et al. Studies evaluating the utility of N-methyl-N-nitrosourea as a positive control in carcinogenicity studies in the $\mathrm{p} 53+/-$ mouse. Int $J$ Toxicol $\mathbf{2 4}$, 349-356 (2005)

24. Reese, J. S., Allay, E. \& Gerson, S. L. Overexpression of human O6-alkylguanine DNA alkyltransferase (AGT) prevents MNU induced lymphomas in heterozygous p53 deficient mice. Oncogene 20, 5258-5263 (2001).

25. Ohgaki, H. et al. Effect of intragastric application of N-methylnitrosourea in p53 knockout mice. Mol Carcinog 28, 97-101 (2000).

26. Clarke, A. R. et al. Thymocyte apoptosis induced by p53-dependent and independent pathways. Nature 362, 849-852 (1993).

27. Lowe, S. W., Schmitt, E. M., Smith, S. W., Osborne, B. A. \& Jacks, T. p53 is required for radiation-induced apoptosis in mouse thymocytes. Nature 362, 847-849 (1993).

28. Wikonkal, N. M. et al. Inactivating E2f1 reverts apoptosis resistance and cancer sensitivity in Trp53-deficient mice. Nat Cell Biol 5, 655-660 (2003).

29. Hoogervorst, E. M. et al. Lack of p53 Ser389 phosphorylation predisposes mice to develop 2-acetylaminofluorene-induced bladder tumors but not ionizing radiation-induced lymphomas. Cancer Res 65, 3610-3616 (2005).

30. Chao, C., Herr, D., Chun, J. \& Xu, Y. Ser18 and 23 phosphorylation is required for p53-dependent apoptosis and tumor suppression. Embo J 25, 2615-2622 (2006).

31. MacPherson, D. et al. Defective apoptosis and B-cell lymphomas in mice with p53 point mutation at Ser 23. Embo J 23, 3689-3699 (2004).

32. Chao, C. et al. Cell type- and promoter-specific roles of Ser18 phosphorylation in regulating p53 responses. J Biol Chem 278, 41028-41033 (2003).

33. Wu, Z. et al. Mutation of mouse $\mathrm{p} 53 \mathrm{Ser} 23$ and the response to DNA damage. Molecular and cellular biology 22, 2441-2449 (2002).

34. Bruins, W. et al. The absence of Ser 389 phosphorylation in p53 affects the basal gene expression level of many p53-dependent genes and alters the biphasic response to UV exposure in mouse embryonic fibroblasts. Molecular and cellular biology 28, 1974-1987 (2008).

35. Lang, G. A. et al. Gain of function of a p 53 hot spot mutation in a mouse model of Li-Fraumeni syndrome. Cell 119, 861-872 (2004).

36. Olive, K. P. et al. Mutant $\mathrm{p} 53$ gain of function in two mouse models of Li-Fraumeni syndrome. Cell 119, 847-860 (2004).

37. Petitjean, A. et al. Impact of mutant p53 functional properties on TP53 mutation patterns and tumor phenotype: lessons from recent developments in the IARC TP53 database. Hum Mutat 28, 622-629 (2007).

38. Wloga, E. H., Criniti, V., Yamasaki, L. \& Bronson, R. T. Lymphomagenesis and female-specific lethality in p53-deficient mice occur independently of E2f1. Nat Cell Biol 6, 565-567; author reply 567-568 (2004).

39. Palacios, G., Talos, F., Nemajerova, A., Moll, U. M. \& Petrenko, O. E2F1 plays a direct role in $\mathrm{Rb}$ stabilization and $\mathrm{p} 53$-independent tumor suppression. Cell Cycle 7, 1776-1781 (2008).

40. Vives, V. et al. ASPP2 is a haploinsufficient tumor suppressor that cooperates with p53 to suppress tumor growth. Genes Dev 20, 1262-1267 (2006).

\section{Acknowledgements}

This research was funded by the Ludwig Institute for Cancer Research. We would like to thank Indrika Ratnayaka for technical assistance.

\section{Author contributions}

The study was designed by E.A.S. and X.L. E.A.S. performed the experiments and analysed the data. The manuscript was written by E.A.S

\section{Additional information}

Supplementary information accompanies this paper at http://www.nature.com/ scientificreports

Competing financial interests: The authors declare no competing financial interests.

How to cite this article: Slee, E.A. \& Lu, X. Requirement for phosphorylation of P53 at Ser312 in suppression of chemical carcinogenesis. Sci. Rep. 3, 3105; DOI:10.1038/srep03105 (2013).

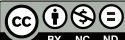

This work is licensed under a Creative Commons AttributionNonCommercial-NoDerivs 3.0 Unported license. To view a copy of this license, visit http://creativecommons.org/licenses/by-nc-nd/3.0 